\title{
Riesgos de la militarización de la seguridad como respuesta a la violencia derivada del narcotráfico. El caso de Colombia y México
}

\author{
Risks of the militarization of security in response \\ to violence derived from drug trafficking. \\ The case of Colombia and Mexico
}

\author{
Martha Elisa Nateras González* \\ Paula Andrea Valencia Londoño*•
}

\begin{abstract}
Resumen
La estrategia de seguridad internacional hace uso de un discurso que privilegia la acción militar como método efectivo para alcanzar la paz y el orden deseados. Dicho discurso, por su alto grado de legitimidad, es incorporado en el orden nacional, y se vincula con nociones como la identidad nacional, la unidad y la seguridad, a partir de conceptos como seguridad nacional, seguridad pública, incluso seguridad ciudadana, para justificar la utilización del ejército en el combate a la delincuencia organizada y el narcotráfico. Su principal riesgo es que puede terminar por oprimir a quien está protegiendo y violentar el respeto a los derechos humanos.
\end{abstract}

Palabras clave: militarización, seguridad, derechos humanos, soberanía estatal.

\begin{abstract}
The international security strategy makes use of a discourse that privileges military action as an effective method to achieve the desired peace and order. This speech, by its high degree of legitimacy, is incorporated into the national order, linking it with notions such as national identity, unity and security, based on concepts such as national security, public safety and even citizen security, to justify the use of the army in the fight against organized crime and drug trafficking. Its main risk is that it may end up oppressing those who are protecting and violating respect for human rights.
\end{abstract}

Keywords: militarization, security, human rights, state sovereignty

\footnotetext{
- Doctora en Ciencias Sociales en el área de Relaciones de Poder y Cultura Política, por la UAM-Xochimilco. Profesora de tiempo completo de Facultad de Ciencias Políticas y Sociales de la UAEM, desde el año 2000. Perfil PROMEP desde noviembre de 2006 y miembro del Sistema Nacional de Investigadores nivel I desde enero de 2014. Ha publicado distintos artículos, capítulos de libros y libros; asimismo, ha asistido a varios congresos nacionales e internacionales como ponente, e impartido conferencias en los temas de cultura política, ciudadanía, desarrollo social, política social, pobreza, seguridad y violencia. Orcid: 0000-0002-7045-1400 / marnateras@yahoo.com.mx._jriosb@unmsm.edu.pe

- Doctora en Ciencias Sociales en la línea de cultura de paz, por la Universidad de Granada. Profesora de tiempo completo de Facultad de Ciencias Sociales y Humanas de la Universidad de Medellín desde el año 20I2; fue coordinadora de la Maestría en Conflicto y Paz de la Universidad de Medellín de 2012 a 2017, y actualmente es coordinadora del Centro de Investigaciones en Ciencias Sociales y Humanas de dicha universidad. Sus últimos artículos en revistas de alto impacto: "Solicitantes de asilo y sus familias en Bodo, Noruega ¿Sin espacio para la resiliencia?" (2018) Autoras: Karla Salazar Serna, Paula Valencia, Migraciones, núm. 44, junio 2018; “Ética del cuidado: lecciones de las mujeres víctimas de minas antipersonal (MAP)", autoras: Sulman Hincapié, Paula Valencia, Opción, año 32, núm. 8I (20I6), y "Expresiones de violencia basada en género en las afectaciones de los ataques por minas antipersonal en Colombia”, autores: Gabriel Ruíz, Paula Valencia, Revista de Dialectología y Tradiciones Populares, Consejo Superior de Investigaciones Científicas, vol. 7I-2, diciembre de 2016. Orcid: 0000-0002-I077-6959 /_pvalencia@udem.edu.co _

Fecha de recepción: 15 de julio de 2019. Fecha de aceptación: 4 de agosto de 2020
} 


\section{Introducción}

Desde la perspectiva clásica, son dos los discursos teóricos que sostienen la belicosidad del Estado frente al clima de violencia e inseguridad que viven algunos países de América Latina, como México y Colombia. Uno es el pensamiento hobbesiano (1980) en torno a la creación del Estado con una función esencial: garantizar la seguridad de las personas y de sus bienes; el otro es el argumento weberiano (1991), que establece que solo el Estado ostenta el uso de la violencia legítima. No obstante, hoy ambas posturas entran en crisis ante la limitada capacidad que ha demostrado el Estado para monopolizar la violencia y detener a los grupos delictivos que desde hace varios años tienen asolada a la sociedad, lo que da razón a la premisa principal de la "Responsabilidad de proteger": "la soberanía entrañaba obligaciones permanentes respecto de la población, al igual que ciertos privilegios internacionales (Naciones Unidas, 2009, p. 7).

Paradójicamente, dicha crisis acentúa las respuestas militaristas desde la perspectiva de securitización, que justifica en lo internacional la injerencia con fines humanitarios en Estados donde los gobiernos se muestran incapaces de asegurar ciertos niveles de protección y de proveer las necesidades básicas de la población (Churruca, 2013) o, en lo nacional, en procesos de militarización de la seguridad ciudadana, cuando las policías locales demuestran incapacidad de protección y se acude a fuerzas armadas en línea directa con la autoridad central para restablecer el orden.

No obstante, la defensa de la soberanía, entendida desde el ejercicio del poder, legitima el uso de la fuerza y la violencia del Estado-Nación como garante de la integridad terri-

I. Concepto incorporado en el ámbito de las relaciones internacionales por la Organización de las Naciones Unidas que transforma la idea de soberanía estatal, para ser interpretada desde la obligación del Estado de responsabilizarse por el bienestar y la protección de su población.

\section{0}


Riesgos de la militarización de la seguridad como respuesta a la violencia derivada del narcotráfico. El caso Colombia y México

torial. En opinión de Hard y Negri (2000), la intervención militar es la forma más frecuente de legitimar un Estado de excepción permanente. La acción militar se constituye, entonces, en una actividad ética, legitimada a través de valores universales, sin estimar el daño que se puede causar a los ciudadanos y a la democracia en sí misma.

Desde los estudios críticos posestructuralistas de la seguridad, en el marco de la biopolítica como gestión gubernamental de la población, Foucault (2006) analiza la institución militar como instrumento permanente de disciplina, y afirma que, a pesar de ser costosa, ha sido fundamental para establecer la paz y el "equilibrio" entre los Estados. Sin embargo, la amenaza y la inseguridad son consecuencia del discurso que soporta dicha política de seguridad, y que se encarga de transmitir la idea de que es indispensable la intervención del Estado, justificándola por la razón gubernamental (Foucault, 2006); así, la seguridad y las amenazas son socialmente construidas y definen las estructuras y relaciones de poder dominantes (Pérez, 2013).

En el contexto de un Estado coercitivo, la función policial y la función de guerra están llegando a un punto de indistinción por el proceso de normalización del discurso del accionar militar frente a las amenazas creadas; esto es, la biopolitización de la función de guerra; es decir, la extensión de un conjunto de prácticas militaristas ancladas institucionalmente y orientadas al control de la población. En este sentido, la militarización de la llamada "guerra contra las drogas" se fundamenta en dos razones: en primer lugar, por ser una amenaza para todas las economías, un tema de seguridad global, y, en segundo lugar, por ser un peligro de alcance transnacional, donde las funciones policiales de combate al narcotráfico deben orientarse hacia una guerra contra el enemigo. Por eso vemos hoy en día que las mismas estrategias que se han utilizado en la guerra contra el terrorismo se están utilizando en la guerra contra 
las drogas, lo que legitima la capacidad coercitiva de los Estados (Corva, 2009).

Este artículo tiene como objetivo problematizar en torno a la intervención de las fuerzas militares como mecanismo para salvaguardar la soberanía del Estado, ante su limitada responsabilidad, intervención militar que ha sido el eje central de la política de seguridad en Colombia y México. Para cumplir con este objetivo, se revisan dos casos de intervención militar, tanto en Colombia como en México, que se presentan ante la opinión pública como eventos coyunturales, pero que nos hacen reflexionar en torno a los discursos de seguridad y las relaciones de poder construidas desde las amenazas, que justifican el uso de la fuerza.

La revisión de estos casos es fundamental para entender dos problemáticas que entraña el modelo de securitización: primero, ambos países centran sus acciones en el mantenimiento de la paz y el orden público ante un imaginario colectivo de amenaza universal y estática (en este caso, los grupos de narcotraficantes), lo que pone en riesgo la gestión democrática y se acerca a regímenes autoritarios ante la limitación de derechos en aras de la seguridad; segundo, existe una permanente necesidad por parte de los Estados nacionales, ante su incapacidad de responsabilizarse de la protección y el bienestar de sus ciudadanos, de incorporar la respuesta militarista cuando se presentan grupos violentos o acciones que trastocan la soberanía de estos Estados, sin estimar el riesgo que existe en materia de vulneración de los derechos humanos (DDHH).

\section{Seguridad ¿nacional, pública, ciudadana o interior?}

En materia de estudios de seguridad se pueden identificar dos corrientes básicas de aproximación: la clásica, de corte eminentemente positivista, y la crítica, que se nutre de corrientes pospositivistas como el constructivismo, la 
Riesgos de la militarización de la seguridad como respuesta a la violencia derivada del narcotráfico. El caso Colombia y México

teoría crítica, el posestructuralismo y el feminismo, entre otras. Esta última corriente, surgida en la post Guerra Fría y fortalecida tras los atentados del 11 de septiembre, cuestiona desde lo ontológico la idea de que la seguridad es estática, objetiva y apolítica, y, desde lo epistemológico, su pretensión de construir teorías universales y duraderas. Para ello concibe la seguridad y la amenaza como factores ideológicos y discursivos, construidos socialmente, que no dan cuenta de una realidad material, como puede ser la presencia de fuerzas militares, sino afincados en creencias, normas e identidades que reflejan una visión del mundo en tanto objetos y valores que deben ser protegidos. Estas ideologías y discursos, a su vez, crean y condicionan las relaciones de poder que deben ser cuestionadas desde una perspectiva descriptiva, como siguiere la Escuela de Copenhague, o que requieren rupturas para conseguir la emancipación humana, como propone la Escuela de Gales (Pérez, 2013).

$\mathrm{Al}$ contrario de esta posición, históricamente, desde los estudios clásicos de seguridad, en su perspectiva positivista, las políticas de seguridad en cada Estado obedecen, entre otras cosas, al tipo de amenaza y el daño causado por ciertas conductas sociales que se consideran factores de inseguridad y nocivas para la población. Por tanto, desde esta perspectiva, el modelo de política de seguridad depende del ámbito de acción, los enfoques utilizados y las políticas públicas que la regulan. Por tal motivo, se identifican múltiples tipologías de la seguridad, entre las que se destacan: la seguridad pública, la seguridad interior, la seguridad nacional, la seguridad internacional, la seguridad humana, y la seguridad ciudadana, entre otras (Angarita, 2013). La mayoría de estos términos se utiliza de manera indistinta cuando se trata de atender los problemas de criminalidad y violencia; sin embargo, es importante dejar claro que sus características y ámbitos de competencia tienden a diferir, 
al igual de la intencionalidad política con la cual fueron conceptualizados.

En este sentido, desde la perspectiva clásica, la seguridad nacional es un concepto que surge en el marco de la Guerra Fría; su objetivo es la defensa del territorio ante cualquier ataque externo; por tanto, el equipamiento militar del Estado para llevar a cabo esta tarea es fundamental. Su enfoque militarista busca eliminar a los enemigos del Estado, sean externos o internos (Delgado, 2008). La seguridad nacional es un término político y su fin es atender las amenazas que ponen en riesgo la estabilidad y la soberanía de un Estado, a contrapelo de las garantías de seguridad que propone la perspectiva crítica y que van en función de la satisfacción de sus necesidades culturales y materiales para la mayoría de los sectores sociales (Piñeyro, 2010). Desde la perspectiva crítica, se comienza a introducir el análisis de múltiples amenazas, muchas de ellas no militares, en una función que trasciende la idea de protección a través del monopolio de la fuerza, y asegura de manera integral el bienestar social.

No obstante, esta difusa integralidad se concreta, según Montero (2013), en dos sentidos de defensa: una a la cual respondería la seguridad nacional en términos clásicos; es decir, frente a amenazas externas al Estado, representadas principalmente por otros Estados, en una clara expresión desde la teoría liberal de la esencia y el deber ser del Estado. Y, por otro lado, desde una perspectiva de seguridad interior, que sería responsabilidad del gobierno y forma parte de la seguridad pública. La seguridad pública es concepto ligado al orden público, y por tanto se orienta a su mantenimiento, así como a la consolidación de la paz a través de dos funciones: una preventiva y la otra punitiva (Ramos, 2005).

Sin embargo, en este marco de seguridad pública, desde hace más de una década se ha promovido la necesidad de vincular una participación cada vez más activa de la ciuda- 
Riesgos de la militarización de la seguridad como respuesta a la violencia derivada del narcotráfico. El caso Colombia y México

danía en la gestión de la seguridad y como corresponsable de la protección. Allí se afinca y toma sentido el concepto de seguridad ciudadana, el cual ubica a la ciudadanía en el centro de las políticas de seguridad y la involucra activamente en el diseño, la instrumentación y la evaluación de las políticas de seguridad (Nateras y Tinoco, 2014).

Además de estas tres categorías conceptuales en materia de seguridad, como se dijo anteriormente, las políticas públicas de los Estados responden al tipo de amenaza que se desea enfrentar (sin olvidar que desde lo estudios críticos sobre seguridad se parte del supuesto de que amenazas y seguridad son construcciones sociales y que, por tanto, dependen, más que de factores materiales, de elementos discursivos). Siguiendo a Angarita (20013), existen dos grandes enfoques que orientan las políticas de seguridad: uno de carácter securitario o militarista, y el otro, de seguridad humana.

El enfoque securitario o militarista concibe la seguridad como fin en sí mismo. El uso de la fuerza es el medio principal para lograr su objetivo central, que es la seguridad del Estado y sus instituciones, aunque esto signifique sacrificar los derechos y las libertades de los ciudadanos (Angarita, 2013). Esto fue evidenciado por la Escuela de Copenhague, al advertir el riesgo en materia de gestión no democrática y militarización que implica la securitización, debido a la pérdida de control democrático y el aumento del poder de las élites (Pérez, 2013). Esta situación es evidente en los casos de Colombia y México, donde las élites locales y nacionales, respectivamente, han encontrado en la militarización, en la conformación de grupos de autodefensa y paramilitares, o ambas, el mecanismo más efectivo para el mantenimiento del statu quo.

El modelo de securitización ha sido bien acogido por distintos países debido al accionar de organismos multilaterales de defensa que han impuesto una visión de paz 
y seguridad occidental, que privilegia las intervenciones militares abiertas y la aplicación de sus postulados. Fue el caso, para el periodo de Guerra Fría, de la Doctrina de Seguridad Nacional (DSN), ${ }^{2}$ y actualmente opera en materia de seguridad internacional bajo el postulado de la "Responsabilidad de proteger".

La DSN se refiere al:

conjunto de principios político-militares vinculados con la seguridad estratégica de Estados Unidos en el marco de la Guerra Fría,formulados en la década de los años sesenta por los ideólogos militares estadounidenses con el propósito de contrarrestar la amenaza comunista en los países del Tercer Mundo (Velásquez, en Angarita, 2013, p. 133).

Es esencialmente una doctrina militar que se ha materializado en algunos países gracias a los acuerdos continentales entre los Estados latinoamericanos, como el tratado de Río de Janeiro (una versión actual de la Doctrina Monroe), a través de la cual pretendió aplicar principios militares a todos los sectores de la sociedad (Angarita, 2013).

Por su parte, la "Responsabilidad de proteger", entendida en un sentido amplio, tal como la formuló Francis M. Deng, exrepresentante del Secretario General sobre los Desplazados Internos, se estructura bajo la premisa de que:

la soberanía concede a los Estados el privilegio de la no intervención en sus asuntos internos, con sujeción a la obligación de asegurar la protección de los derechos humanos de sus ciudadanos y de todos los individuos que se encuentren en su territorio (Naciones Unidas, 2003, p. 5).

2. Al amparo de la DSN, Estado Unidos ha dado apoyo a las dictaduras militares del continente, ha llevado a cabo intervenciones encubiertas $y$ ha violado todo tipo de derechos en países como: República Dominicana, Haití, Cuba, Nicaragua, Panamá, Chile, Colombia y Venezuela (Angarita, 2013).

\section{6}


Riesgos de la militarización de la seguridad como respuesta a la violencia derivada del narcotráfico. El caso Colombia y México

Sin embargo, la excusa de la ausencia de protección estatal a los derechos humanos de sus ciudadanos ha dado lugar a las múltiples intervenciones con "fines humanitarios" que hemos observado en el mundo durante las últimas décadas: Somalia, Bosnia y Kosovo, por mencionar las más sonadas; intervenciones que obligaron en 1999 a un llamamiento del Secretario General de Naciones Unidas para buscar formas de conciliar el respeto por la soberanía de los Estados y la necesidad de actuación frente a violaciones masivas de los DDHH (Churruca, 2013).

Esto da origen, a partir del Informe de la Comisión Internacional sobre Intervención y Soberanía de los Estados, en 2001 a la conceptualización de la "Responsabilidad de proteger", responsabilidad que se estructura a partir de tres pilares: 1. Responsabilidad del Estado de proteger a sus poblaciones. 2. Responsabilidad de la comunidad internacional de ayudar a los Estados a proteger a sus poblaciones. 3. Responsabilidad de la comunidad internacional de proteger a las poblaciones de un Estado cuando es evidente que este no logra hacerlo (Šimonović, s/f). Como afirma Churruca (2013, p. 255), la comprensión de este tipo de responsabilidades abre "el camino para entender la soberanía estatal como una cuestión de responsabilidad y no solo de poder", y permite, por lo menos en teoría, pasar del enfoque militarista a la protección como prevención, lo que posibilita el acercamiento al segundo enfoque descrito por Angarita (2013): la seguridad humana. No obstante, cabe resaltar que la mayor parte de las acciones internacionales enmarcadas en este postulado se han estructurado bajo la responsabilidad de reaccionar, por ello, la intervención militarista sigue teniendo un lugar privilegiado.

El enfoque de seguridad humana aparece mencionado por primera vez en el Informe sobre Desarrollo Humano (1994); en él se afirma que: 
Actualmente, para la mayoría de las personas, el sentimiento de inseguridad se debe más a las preocupaciones acerca de la vida cotidiana que al temor de un cataclismo en el mundo. La seguridad en el empleo, la seguridad del ingreso, la seguridad en la salud, la seguridad del medio ambiente, la seguridad respecto del delito: son estas las preocupaciones que están surgiendo en todo el mundo acerca de la seguridad humana (PNUD, 1994, p. 3).

El enfoque de seguridad humana tiene interpretaciones polisémicas debido a la amplitud que ha tenido en su formulación inicial, y la aproximación que a él hacen los diferentes autores. En términos generales, es posible identificar dos corrientes predominantes en materia de seguridad humana: el enfoque amplio, el cual

se centra en la "libertad respecto de la necesidad", esto es, en la satisfacción del desarrollo humano y de un mínimo de bienestar (...) y el enfoque restringido [que] se centra en la "libertad respecto del miedo" esto es, en la protección ante la violencia física en contextos de conflicto (Churruca, 2013, p. 252).

Muchos autores prefieren hacer su lectura de la seguridad humana desde el segundo enfoque, y por ello su aproximación a la seguridad parte de la prevención de la violencia física, acercando la seguridad humana a los temas de seguridad ciudadana. No obstante, la seguridad humana, en su acepción más amplia, supera la simple implementación de medidas de orden público e involucra la protección de otras esferas del individuo, para algunos acotadas a partir de los siete tipos de amenazas para la seguridad humana definidas por la Organización de las Naciones Unidas (seguridad económica, seguridad alimentaria, seguridad sanitaria, seguridad medioambiental, seguridad personal, seguridad comunitaria, seguridad política), y para otros mucho más flexibles y adaptables a cada concepto. 
Riesgos de la militarización de la seguridad como respuesta a la violencia derivada del narcotráfico. El caso Colombia y México

Sin embargo, desde los estudios críticos de seguridad, esta aproximación a la solución de los problemas derivados de amenazas universales e inmutables no debiera ser la pretensión de la seguridad. Esta debería propender a la ruptura de las relaciones inequitativas de poder de las que se derivan las amenazas a la forma de vida que valoramos vivir. Por ello, para autores como Duffield, el concepto de seguridad humana da cuenta del marco de gobernanza global, liberal y hegemónico, en una clara interconexión con el concepto de desarrollo (Pérez, 2013). Por su parte, Shani (citado por Pérez, 2013) afirma que la seguridad humana minusvalora e incluso ignora el contexto cultural, estos discursos, prácticas y valores deben ser leídos como la representación de unas identidades diversas, las cuales garantizan la dignidad, para trascender de la protección ante la violencia física o la satisfacción de necesidades materiales, a una recuperación del bios (en palabras de Agamben) a partir del rescate de la historia y las raíces.

Lejos de este debate, en algunos países de América Latina, como Colombia y México, prevalece el enfoque reactivo y militarista de la seguridad, el cual ha demostrado ser poco eficaz en el combate a la criminalidad, además de vulnerar los DDHH. Sin embargo hoy, como afirma Angarita (2013), esta perspectiva militarista se encuentra encubierta bajo un modelo de seguridad ciudadana, el cual se ha promocionado como la respuesta de los Estados democráticos al problema del incremento de la violencia y la criminalidad, al sostenerse en el supuesto de la participación ciudadana como mecanismo de legitimación. La seguridad ciudadana es, según el autor, la misma DSN, que mantiene su carácter militarista, pero que al presentarse con otros nombres le da formalmente un sentido más democrático y de respeto de los derechos humanos, y por ser ciudadana le permite incorporar a la sociedad en sus funciones represivas y de persecución o eliminación de opositores políticos (Angarita, 2013). 
Por otro lado, es importante tomar en cuenta que en América Latina un número significativo de países pasaron por regímenes autoritarios o han sufrido los embates de conflictos internos y, por tanto, han construido una cultura política que legitima las soluciones de "tolerancia cero" y "mano dura"; esto implica que el ejercicio de la violencia está asimismo legitimado. Por eso, como dice Carrillo (2007), no deja de ser paradójico que los "regímenes democráticos" de América Latina, por diferentes vías, tratan de atemperar los efectos de la violencia que provoca la exclusión y la falta de respeto a los DDHH con apuestas políticas en materia de seguridad que llevan implícitamente aparejada la posibilidad del accionar desde el ejercicio de la función militar.

El Plan Colombia y el Plan Mérida son el ejemplo más claro de cómo la militarización de la función policial se ha transnacionalizado a través de la guerra contra las drogas. Armar al ejército y la policía de ambos países es elemento fundamental del paquete de ayuda militar por parte de Estados Unidos a México y Colombia para combatir el narcotráfico y el crimen organizado (Corva, 2009). El objetivo final es proteger a los Estados nacionales de las irrupciones que puedan alterar el statu quo en el orden internacional. Esta estrategia de "protección nacional" atenta contra la soberanía; no obstante, los Estados nacionales la hacen parecer necesaria para proteger de las amenazas exteriores, pero en el interior puede tener un resultado inverso, el de oprimir y reprimir al que está protegiendo (Hardt y Negri, 2000).

Si bien la utilización del ejército en el combate a la delincuencia organizada y al narcotráfico es una decisión de política interna de los Estados, hacer uso de él es parte de la estrategia de seguridad internacional y, por lo tanto, el discurso internacional legitima el uso de todos los aparatos de seguridad del Estado para atender esta problemática y lograr la pacificación de las distintas regiones del mundo. 
Riesgos de la militarización de la seguridad como respuesta a la violencia derivada del narcotráfico. El caso Colombia y México

Sin embargo, la intervención de las fuerzas militares es un mecanismo eficiente para salvaguardar la soberanía del Estado; esta injerencia es la forma más común de legitimar un Estado de excepción permanente que, según Agamben (2005), se ubica en un umbral de indeterminación entre democracia y absolutismo; por lo tanto, no está fuera del orden jurídico, pero tampoco está dentro, pues se sitúa en una zona de indefinición. Sobre este supuesto girarán los tres casos de estudio que se presentan a continuación.

2. La militarización de la seguridad ciudadana: los discursos de seguridad y las relaciones de poder que construyen amenazas. Los casos de Colombia y México

La discusión sobre los riesgos del modelo de securitización y sus impactos en el control democrático y el otorgamiento de poder a las élites es claramente ilustrable con los casos de Colombia y México, a pesar de sus notables diferencias. Si bien es cierto que el fuerte énfasis militarista otorgado a la seguridad en Colombia se justifica en parte por su prologada situación de conflicto armado no internacional, desde hace más de tres décadas este país presenta un proceso de imbricación de múltiples violencias, unas ligadas al componente sociopolítico derivado del periodo de "La violencia", ${ }^{3}$ y que permitió el surgimiento de grupos guerrilleros y paramilitares, con sus respectivas élites políticas locales, y otras vinculadas a los actores armados inmersos en la cadena de producción, tráfico y comercialización de narcóticos, claramente emparentados con élites tradicionales por su apoyo financiero en el escenario de crisis industrial de los 80 y 90 , o por su ingreso a la élite terrateniente (Valencia, 2018). A pesar de que no todas estas violencias implicaban un riesgo

3. Denominación otorgada en Colombia al periodo de la lucha bipartidista entre liberales y conservadores, lucha que se prologó desde finales de la década del 40 hasta finales de la década del 50. 
para la soberanía nacional, la respuesta predominante en todos los casos fue la militarización.

En el caso mexicano, la ausencia de una situación de conflicto armado interno hace mucho más evidente el trasfondo político que subyace a la decisión de asumir un modelo de securitización, donde las fuerzas militares son la regla y no la excepción. Así, la pérdida del control autoritario del Partido Revolucionario Institucional (PRI), y el debilitamiento de sus procesos de cooptación de los caciques locales, obligó al Partido Acción Nacional (PAN) a su llegada al poder, a implementar una política de "mano dura" donde las fuerzas militares adquirieron un papel protagónico (Valencia, 2018) y hoy respalda una Ley de la Guardia Nacional en la que el uso policial de las fuerzas militares es la regla y no la excepción.

En ambos casos, la legitimación del modelo militarista se estructuró bajo un discurso de conservación del orden interno ante amenazas e intrusiones derivadas, entre otras, de economías ilegales trasnacionales que de nuevo demuestran la incidencia del discurso internacional de lucha contra el terrorismo trasladado a la problemática del narcotráfico, y que justifica, a los ojos de la sociedad, la limitación de derechos en aras de la seguridad como protección de la soberanía y la legalidad.

2.I La militarización en zonas urbanas, el tránsito de la actuación en conflicto armado a la actuación en escenarios de violencia armada urbana en Medellín y sus riesgos en materia de $\mathrm{DDHH}$

En el caso colombiano, dos fenómenos que parecen actuar de forma aislada en otros contextos, conflicto armado interno y violencia criminal, demuestran claras correlaciones. Como afirman Gil y Alonso (2009), es posible identificar relaciones tanto de colaboración como de antagonismo entre los diferentes actores armados, tanto legales como ilegales, de 
Riesgos de la militarización de la seguridad como respuesta a la violencia derivada del narcotráfico. El caso Colombia y México

izquierda y derecha, con estructuras vinculadas al crimen organizado, en especial al narcotráfico. No obstante, esta confluencia entre actores armados de múltiples orígenes no lleva a desconocer que, en Colombia, y particularmente en Medellín, a diferencia de gran parte de los fenómenos de violencia armada urbana presentes en las ciudades latinoamericanas, se dio un proceso de urbanización del conflicto armado que permitió la incursión de manera coyuntural de las fuerzas militares en el entorno urbano.

Los orígenes de la urbanización del conflicto armado en Colombia se pueden hallar en la década del setenta, cuando el Ejército de Liberación Nacional (ELN) insertó estructuras armadas en la ciudad bajo la figura, en primera instancia, de milicias urbanas. Durante la década de los 80, se observó la presencia del Movimiento 19 de Abril (M-19), quien identificó los centros urbanos, no solo como zonas de abastecimiento, sino también como espacios privilegiados para su labor proselitista ante otros movimientos sociales (Medina, 2001). Sin embargo, esta labor proselitista en los centros urbanos se complementó con labores de administración de justicia y oferta de seguridad en los barrios, funciones que permitieron a los miembros de los movimientos subversivos ganar legitimidad y consolidar una estrategia de control territorial y social. A la par de la incursión urbana de la guerrilla en la década de los 80, estructuras paramilitares empiezan a ver en la ciudad un atractivo espacio de operaciones militares, en especial, por la fuerza tomada por el contexto urbano para el accionar de organizaciones criminales ligadas al narcotráfico.

Entre 1985 y 1993, se puede afirmar que existió el dominio absoluto de la ciudad por parte del Cartel de Medellín, dominio en el que tuvieron gran relevancia organizaciones sicariales como la banda La Terraza, que, entre 1984 y 1998, monopolizó la actividad armada en la ciudad. Entre 1990 y 1994, debido a la fuerte persecución internacional 
al Cartel de Medellín, este modelo de confrontación varió, lo que permitió un auge de las milicias urbanas asociadas con las FARC, el ELN y la llegada grupos paramilitares pertenecientes a las Autodefensas Unidas de Colombia (AUC).

Este fenómeno fue la puerta de entrada para el fortalecimiento de la lucha urbana de las milicias del ELN, bajo la estrategia de reclutamiento de miembros de los grupos armados presentes en los barrios; sin embargo, el proyecto resultó inviable por no contar con capacidad para controlar las milicias, formadas en gran parte por jóvenes con desapego de la ciudad, sin formación política, inmersos en el consumo de drogas y con problemas de resentimiento y desadaptación social, lo que les impedía seguir la disciplina y la obediencia jerárquica, además de los altos costos que implicaba su sostenimiento (Defensoría del Pueblo, 2004). En consecuencia, en 1994, tras un proceso de negociación con la alcaldía de Medellín, aproximadamente 700 hombres de las milicias urbanas se desmovilizaron y conformaron la Cooperativa de Vigilancia y Servicios Comunitarios (COOSERCOM) (Defensoría del Pueblo, 2004).

Esto complejizó la dinámica de las hegemonías criminales en la ciudad, pues a la par de la creación de COOSERCOM se crearon entre 1995 y 1997 las Cooperativas de Seguridad Convivir, como política de gobierno para el apoyo a la seguridad en Antioquia (Defensoría del Pueblo, 2004). Sin embargo, no todos los desmovilizados se unieron a estas cooperativas de seguridad, muchos de ellos optaron por conformar bandas dedicadas a la delincuencia común, lo que Aricapa (2005) llama, citando otros sociólogos, la bandolerización de las milicias. En 1996 surge una nueva organización, los Comandos Armados del Pueblo (CAP), que como afirma Aricapa (2015) dan cuenta del fenómeno contrario, la milicianización de las bandas. Estos grupos surgen "como fórmula de seguridad frente al accionar de bandas, 
Riesgos de la militarización de la seguridad como respuesta a la violencia derivada del narcotráfico. El caso Colombia y México

pero con un ingrediente político de izquierda, y asociados al ELN" (Gil y Alonso, 2009).

Esta múltiple representación de actores y tendencias políticas y criminales hace que el escenario de la ciudad de Medellín sea cada vez más complejo y se haga más sutil la distinción entre grupos delincuenciales, milicias de izquierda y bandas vinculadas con el negocio del narcotráfico, razón por la cual, aunque el velo del Derecho Internacional Humanitario (DIH) cubrió las operaciones militares que se describieran a continuación, bajo el discurso de atacar las milicias del ELN y las FARC presentes en la Comuna $13^{4}$ como principal amenaza al orden interno, el antagonismo y la complementariedad entre fuerzas armadas y grupos armados ilegales, estas operaciones han sido una constante en la historia de la ciudad y marcan la difícil distinción entre el accionar en el marco del DIH o basado en el Derecho Internacional de los Derechos Humanos (DIDH). A continuación se describen dos operaciones militares emblemáticas que dan cuenta de los riesgos existentes en materia de pérdida de control democrático, al extender el ámbito de actuación del Ejército y permitir su intervención en escenarios de violencia, en especial en el ámbito urbano.

\section{El caso de las operaciones Mariscal y Orión}

El año 2002 fue para la Comuna 13 de Medellín uno de los sectores más conflictivos de la ciudad, el año que marcó su historia social y política reciente. La Comuna 13 es una de las dieciséis comunas que integran la división político administrativa de la ciudad, está formada por veinte barrios y numerosos asentamientos informales producto de invasiones, ventas ilegales y barrios piratas, en los cuales se asienta aproximadamente el $6 \%$ de la población total de

4. Denominación político administrativa utilizada para llamar a las agrupaciones de barrios que comparten la participación en una misma junta administradora local. 
la ciudad (138,063 habitantes, según proyecciones a 2015) (Aricapa, 2015).

Entre los asentamientos más destacados se encuentran: El salado, Veinte de Julio, Santa Rosa de Lima, Juan XXII, Belencito, y Las Independencias I y II. Como afirma Aricapa (2015), en estos asentamientos "en cosa de cinco años se acomodaron más de cinco mil familias, lo que en su momento le valió ser considerada la invasión más voraz de América Latina" (Aricapa, 2015). Este proceso de alta densificación fluyó en vía directa con el discurso internacional construido alrededor de los riesgos de la urbanización acelerada en periferia y sus fenómenos de violencia, ${ }^{5}$ haciendo que la respuesta institucional, en lugar de preventiva fuera reactiva, en especial contra los jóvenes, que siguen siendo rotulados como los principales victimarios.

Por ello, la presencia militar en la zona no fue un asunto intempestivo; durante el proceso de consolidación de los asentamientos, y en la labor de tocar puertas por parte de los líderes de la comunidad para conseguir el acceso a bienes y servicios, el sector de San Javier fue incluido en la acción cívico militar de la Cuarta Brigada del Ejército. Con ello se consiguió que se priorizara como inversión para el sector la dotación de la escuela, de acuerdo con la solicitud unánime de la comunidad (Aricapa, 2015), legitimando con una financiación mínima, pero en consonancia con las necesidades expresadas por la comunidad, la presencia y el accionar de las fuerzas militares en el sector. Luego, en el año 2002, año de los mayores eventos en materia de confrontación armada en la zona, se dio vía libre a la iniciativa de construcción de una base militar en la zona, iniciativa que solo se pudo

5. Para la OCDE el predominio de la violencia armada urbana en los contextos latinoamericanos se debe a las transformaciones generadas por la migración rural urbana, que ha engrosado los focos de miseria en grandes ciudades alrededor del mundo, con una consecuente falta de oportunidades, en especial para los jóvenes, en estos grandes centros urbanos. Ver: Declaración de Ginebra sobre Violencia y Desarrollo (2006).

\section{6}


Riesgos de la militarización de la seguridad como respuesta a la violencia derivada del narcotráfico. El caso Colombia y México

concretar en 2008, año de su inauguración en el barrio Las Independencias, debido a los múltiples obstáculos generados por los actores armados presentes en la zona.

A la par de la presencia militar, desde el discurso oficial "esporádica”, en la zona (antes de la construcción de la base militar), a inicios de los 90, desde la parte alta del sector comenzaron a ingresar hombres encapuchados y armados, llamados por los pobladores los "caretrapos" (Aricapa, 2015), actores armados con los que los pobladores tenían una relación distante pero ineludible. Estos inicialmente pertenecían, según testimonios de la comunidad, al ELN, y posteriormente su lugar fue copado por los CAP y los grupos de autodefensa.

Los enfrentamientos entre grupos armados ilegales y el naciente fenómeno de desplazamiento forzado intraurbano se convierten en las amenazas que justifican que, entre febrero y octubre de 2002, se realizaran once operativos militares en territorios que se consideraban controlados por la guerrilla (Centro Nacional de Memoria Histórica - $\mathrm{CNMH}-$, 2014): operación Primavera, a inicios de febrero de 2002; operación Otoño, en la última semana de febrero del mismo año; operación Mariscal, el 21 de mayo de 2002; operación Potestad, el 15 de junio de 2002; operación Antorcha, el 15 de agosto de 2002 y la operación Orión, que se inicia el 16 de octubre de 2016. Entre ellas, las principales operaciones fueron Mariscal y Orión (Aricapa, 2015).

La operación Mariscal fue realizada el 21 de mayo de 2002, desde las 3 a.m. hasta las 3.30 p.m. (CINEP, 2003). Tenía como objetivo desarticular un supuesto plan terrorista de la guerrilla para sabotear las elecciones presidenciales que se llevarían a cabo el 26 de mayo. La operación se inició cuando el Ejército, con sus tanques blindados, destruyó el transformador de energía que surtía del servicio a los barrios 20 de Julio, El Salado, Las Independencias y Nuevos Conquistadores. En ella intervinieron alrededor de mil efec- 
tivos de la Policía, el Ejército, el Departamento Administrativo de Seguridad (DAS), el Cuerpo Técnico de Investigación de la Fiscalía (CTI), la Fuerza Aérea Colombiana (FAC), la Fiscalía General de la Nación y la Procuraduría General de la Nación, y se hizo uso de ametralladoras M60, fusiles, helicópteros artillados y francotiradores. En la operación murieron nueve civiles, entre ellos niños, y aproximadamente 37 resultaron heridos; además de que 55 personas fueron detenidas arbitrariamente (CINEP, 2003). La cifra oficial de víctimas coincidió en las muertes con los datos anteriores, pero frente a los heridos y los capturados defirió con un informe de 39 heridos de los cuales 31 fueron civiles, dos soldados y seis policías, y 31 capturados (Aricapa, 2015).

A esto se suman otras denuncias de ataques a la población civil y detenciones arbitrarias, además de infracciones directas al DIH en materia de protección a la misión médica y los bienes civiles. Ejemplo de ello es que el comando de la operación se estableció en la unidad hospitalaria del sector.

Asimismo, "miembros de la Fuerza Pública ingresaron en varias viviendas y las registraron sin orden judicial (...) Algunas casas fueron tomadas como trincheras por los policías" (CINEP, 2003, p. 15). Informes de organizaciones de DDHH, construidos sobre la base de información interceptada de la radiofrecuencia del Ejército, dan cuenta "Del carácter indiscriminado con que fueron empleadas las armas y medios de combate por parte de la Fuerza Pública" (CINEP, 2003). Aricapa (2015) afirma que alrededor de 130,000 personas quedaron atrapadas en sus casas en medio del enfrentamiento. La operación terminó debido a la presión de los medios de comunicación y los habitantes del sector, quienes con pañuelos blancos salieron a las calles a pedir el cese al fuego.

Con posterioridad a este operativo, en medio del constructo social estructurado alrededor de la Comuna 13, como la mayor amenaza a la seguridad nacional y el orden 
Riesgos de la militarización de la seguridad como respuesta a la violencia derivada del narcotráfico. El caso Colombia y México

interno en Colombia, el 16 de octubre de ese mismo año, bajo el mandato presidencial de Álvaro Uribe Vélez, y en el marco de su nueva política de seguridad nacional, se da la siguiente gran operación, Orión, la cual es denominada por el Centro Nacional de Memoria Histórica (CNMH) como "la acción armada de mayor envergadura que ha tenido lugar en un territorio urbano y en el marco del conflicto armado en el país" (CNMH, 2014). Esta operación cubrió los barrios Belencito-Corazón, 20 de Julio, El Salado, Las Independencias y Nuevos Conquistadores, y se prologó por todo el mes de noviembre y parte de diciembre de 2002. Al contrario de la operación Mariscal, Orión fue iniciativa directa de la Presidencia de la República, luego de una solicitud expresa de intervención por parte del alcalde de Medellín. Contó con cuatrocientos hombres especializados en operaciones urbanas (Aricapa, 2015) y en ella participaron "efectivos del ejército, la policía, el DAS e integrantes del cTI, así como hombres y mujeres informantes vestidos de camuflado y encapuchados, y miembros de la Fiscalía, Personería y Procuraduría General de la Nación” (CINEP, 2003, p. 20). Como se logra observar, esta es una política reactiva ante la incapacidad de proteger desde la prevención.

Esta operación demostró nuevamente la pérdida de control democrático en la zona, la restricción de libertades en aras de la "seguridad", y el accionar mancomunado legal e ilegal para lograr el control territorial. "La población civil fue atacada indiscriminadamente por la Fuerza Pública, utilizando ametralladoras, fusiles y helicópteros artillados desde los cuales se causaron averías en múltiples viviendas y decenas de víctimas civiles" (CINEP, 2003). El balance en materia de afectación a la población civil fue de un muerto, 38 heridos, varios de ellos menores de edad, ocho personas desaparecidas, 355 detenidos y 170 de ellos judicializados (CINEP, 2003). No obstante, según el informe oficial de la operación, murieron cuatro militares, tres civiles y diez 
milicianos, y treinta quedaron heridos, de los cuales diez eran militares (Aricapa, 2015).

En cuanto al elevado número de detenidos, se presentó un cúmulo de irregularidades en el debido proceso, algo, como afirma Aricapa (2015), sin precedentes en la historia colombiana, pues se contó con "informantes con el rostro cubierto con capucha, que iban en medio de los piquetes de policía - a veces uniformados de policías ellos tambiénseñalando casas y personas", en una clara vulneración del principio de distinción.

Adicional a esto, el accionar de grupos paramilitares, en un claro quebrantamiento del monopolio legítimo de la fuerza, produjo sus propias consecuencias. Según afirman los pobladores, escuadrones de la muerte en la noche sacaban a las personas de sus casas para ejecutarlas.

Lo prologado de la operación también generó problemas de acceso a bienes y servicios para la población, y provocó una situación de confinamiento que en gran parte de los casos se transformó en desplazamientos internos forzados. Como afirmó un líder comunitario del barrio 20 de Julio al CINEP, "Antes y durante la Operación Orión el éxodo de familias fue casi total" (CINEP, 2003).

En menos de seis meses, el discurso de amenaza al orden interno, construido sobre la base de la presencia de milicias urbanas de la guerrilla, permitió, bajo el supuesto de lucha antiterrorismo, consolidar el control territorial de los Grupos de Autodefensa en el corredor oriental, zona de trasiego fundamental de la droga que circulaba del sur del país hacia el golfo de Urabá. Paradójicamente, el traslado del control territorial de las milicias guerrilleras a los grupos paramilitares fue el germen en Colombia para construir la política de "Seguridad Democrática", ampliamente difundida por el presidente Uribe y que le vale el crédito para el común de la ciudadanía de recuperar el orden democrático, en clara consonancia con la definición de Angarita (2013) del 
Riesgos de la militarización de la seguridad como respuesta a la violencia derivada del narcotráfico. El caso Colombia y México

enfoque militarista, una seguridad como fin en sí misma, donde el uso de la fuerza es el medio principal para garantizar la seguridad del Estado y sus instituciones, aunque esto signifique sacrificar los derechos y libertades de los ciudadanos.

\subsection{La ofensiva militar en contra del narcotráfico}

\section{y la delincuencia organizada en México}

La participación de las Fuerzas Armadas Mexicanas (FAM) en el control del crimen organizado ha sido una constante y no un asunto coyuntural, como el gobierno ha venido argumentando, para legitimar su inclusión en las políticas de seguridad. Astorga (2007) señala que desde hace muchos años ha existido una lucha por mantener la hegemonía del poder político y una búsqueda de mayor autonomía por parte de los traficantes, lo que ha provocado una lucha violenta. Lo cierto es que la intervención militar en las tareas de seguridad ha crecido considerablemente en los últimos quince años debido, según Piñeyro (2010), a los impactos sociales negativos de las crisis económica y política, la menor capacidad de mediación de las instituciones del Estado mexicano, el fortalecimiento del crimen organizado, y en particular del narcotráfico, entre otros, y a la recomposición de las élites política y económica a causa de la transición "democrática".

El primer operativo en contra de los cultivadores de marihuana y adormidera en México data de 1941, por parte de las autoridades de Sinaloa. Esto provocó una ofensiva violenta por parte de los narcotraficantes en contra de la policía judicial, como advertencia al gobierno y a la población (Paoli, 2008). Para hacer frente a las actividades ilícitas que estaban creciendo en varias regiones del país, a partir de 1947, dos instituciones van a ser fundamentales en el combate al consumo y la venta de drogas: la Secretaría de Salud y la Procuraduría General de la República (PGR). Posteriormente se creó la Dirección Federal de Seguridad 
(DFS), dependencia centralizada que asumiría las funciones de control y regulación del narcotráfico. ${ }^{6}$ Esta institución va a ser fundamental en el control y puesta en marcha de las campañas antinarcóticos en los siguientes años (Palacios y Serrano, 2010).

Durante las décadas del 40 y el 50, las autoridades mexicanas desarrollaron un enfoque punitivo contra quienes se dedicaban a traficar drogas ilegales, aumentando las penas y dedicando un número creciente de soldados a la labor de erradicación de cultivos ilegales. No obstante, el problema creció en la década de 1960, por el aumento en el consumo de drogas ilegales en Estados Unidos, lo que provocó que el gobierno de Richard Nixon pidiera una mayor colaboración de México en el combate al tráfico de la marihuana y heroína que tenía como destino ese país (Chabat, 2010).

Cabe señalar que, entre 1950 y 1970, los grupos que se dedicaban al contrabando y a la venta de enervantes estaban diseminados, no existía un poder central y tampoco había alguna organización visible que estuviera por encima de las demás (Ravelo, 2011).

Durante la década de los setenta empezó a gestarse el poderío de la organización del Golfo, en primer lugar por tener una posición geográfica privilegiada; es decir, por estar ubicados en la frontera, pero además porque en estos años la presencia de autoridades federales era irregular y precaria y, además, el tráfico de droga era incipiente, porque el contrabando de artículos diversos seguía siendo su actividad más importante y su producto principal era la marihuana (Saldivar, 2016).

Por ello, la primera ofensiva militar, que da inicio a la guerra contra las drogas en México, se lleva a cabo el 30 de septiembre de 1976; esta maniobra dirigida por militares se conoció como Plan Cóndor y se efectuó en los estados las drogas ilícitas de 1947 a 1985. 
Riesgos de la militarización de la seguridad como respuesta a la violencia derivada del narcotráfico. El caso Colombia y México

de Chihuahua, Sinaloa y Durango. Su balance para las fuerzas militares "un éxito porque en su informe señalan haber destruido alrededor de 15 millones 800 mil metros cuadrados de cultivos de amapola y marihuana" (Valdez, 2009, p. 35); sin embargo, en materia de derechos humanos las consecuencias no se podían ocultar "Cerca de 100 mil personas, tan solo en el caso de Sinaloa, huyeron a los centros urbanos" (Valdez, 2009, p. 35). Un año después se realizó el Plan Canador; sin embargo, "la corrupción del sistema priista manipuló el operativo y solo fueron detenidos pequeños campesinos dedicados a la siembra, pues los capos del narcotráfico huyeron, refugiándose en Guadalajara” (Valdez, 2009, p. 35).

Si bien estos operativos lograron reducir el tamaño de la economía ilegal, los traficantes de drogas mostraron su enorme capacidad para reorganizarse y adaptarse a las nuevas circunstancias. Tanto estas operaciones como las subsecuentes recibieron todo el apoyo de Estados Unidos; no obstante, a la larga, lejos de disminuir el problema, el narcotráfico empezó a crecer más. El negocio no solo se amplió, también se diversificó y se empezó a cotizar mejor debido a la prohibición (Enciso, 2010).

Esa incapacidad o falta de una estrategia de combate al narcotráfico tiene que ver con una especie de pacto con sus miembros, pues, con el fin de evitar la violencia extrema, el gobierno decidió tolerarlo. ${ }^{7}$ Esta política de tolerancia es la que explica, en parte, por qué, hasta mediados de 1980, el combate a la delincuencia organizada no ocupaba un lugar destacado en la agenda del gobierno mexicano, situación que cambia cuando empieza la exportación masiva de cocaína colombiana hacia Estados Unidos. Es ahí cuando México

7. Esta tolerancia está asociada a la incapacidad del Estado para aplicar sus propias leyes, situación que lo lleva a tomar dos alternativas a corto plazo: o se toleran los delitos o se confrontan de manera ineficiente. Empero, ambas opciones son muy malas y tienen altos costos: corrupción o violencia (Chabat, 2010). 
se convierte en lugar de paso, lo cual inevitablemente fortaleció a los grupos de narcotraficantes que operaban en el país (Enciso, 2010).

Como afirma Astorga (2007), la lógica del Estado centralista autoritario priista fue fundamental en el control del tráfico de drogas y de la violencia que de manera natural genera este negocio ilícito, durante cuarenta años aproximadamente (1947-1985), pues incluso la corrupción se centralizó.

En los años setenta, el Ejército fue utilizado para perseguir guerrilleros y movimientos sociales de protesta. Desde los años noventa, las FAM intervienen en la protección de las fronteras y en contra de movimientos de protesta o insurgentes antigubernamentales y contra el narcotráfico, y actualmente en el combate a la criminalidad y a la delincuencia organizada. ${ }^{8}$

Con el fin de la hegemonía priista, la estructura del poder político se dispersó, y se perdió el respaldo de las instituciones coercitivas del Estado a los políticos de las regiones periféricas; esto impidió que su poder se impusiera sobre los narcotraficante, y estos, a su vez, al contar con mayores recursos, empezaron a construir sus propias bases clientelares (Duncan, 2014). Con el cambio del partido en el poder, en el año 2000, la dinámica del gobierno no sufrió grandes modificaciones; una muestra de ello es que las políticas de atención al narcotráfico no experimentaron un cambio radical. De hecho, se continuó con la militarización de las corporaciones policiacas, y el Ejército mantuvo su participación en tareas de seguridad pública.

En este cambio de fuerzas, para la creación y consolidación de clientelas, los narcotraficantes comenzaron a

8. En la década de 1990 los militares empiezan a tener un papel más protagónico en la vida nacional, al lanzar una ofensiva integral en contra del Ejército Zapatista de Liberación Nacional (EZLN); por tanto, la cúpula militar llevó a cabo una profunda reestructuración de las FAM, organizando e integrando comandos de élite, capacitados para actuar en todo tipo de contextos geográficos (Sandoval, 2000). 
Riesgos de la militarización de la seguridad como respuesta a la violencia derivada del narcotráfico. El caso Colombia y México

satisfacer las demandas materiales de muchos sectores de la sociedad que estaban fuera de la distribución del poder político; esto les permitió imponer sus propias instituciones de control y seguridad. En poco tiempo, los delincuentes empezaron a ejercer funciones de vigilancia y administración de justicia, reemplazando así a las autoridades del Estado en comunidades y regiones productoras de droga.

La política de tolerancia que había caracterizado al Estado mexicano en las décadas de 1970 y 1980 cambió, pero con resultados adversos, pues, a pesar de que el gobierno del presidente Vicente Fox logró la captura de varios capos, la cantidad de droga traficada a Estados Unidos no disminuyó y las bandas del narco siguieron operando, debido a que no se desarticuló la estructura operacional, de mercadeo y financiera de esos grupos delictivos (Chabat, 2010).

\subsection{La militarización de la seguridad pública}

en México: un ejemplo paradigmático

Considerando que la estrategia de seguridad pública federal antinarcóticos es de corte represivo y reactivo, frente al aumento exponencial de la incidencia delictiva, la política que se ha aplicado es de "mano dura" en el plano físico y legal, aun cuando ya se dijo que esto va en contra del discurso democrático. Sin embargo, la falta de coordinación y cooperación interinstitucional entre los órganos del Estado, tanto civiles como militares, ha sido la constante.

Las FAM tienen dos facultades constitucionales básicas: la conservación del orden interno y la defensa externa, y ambas responsabilidades comprenden un conjunto de misiones encaminadas es proteger al Estado frente a amenazas externas o internas por parte de otros Estados o de actores no estatales (Piñeyro, 2010). Esto obviamente excluye la tarea de proteger a la población mediante actividades relacionadas con la seguridad pública, función que corresponde a las instituciones policiacas. 
El caso que aquí se presenta es la muestra de cómo el Estado justifica la incursión de las FAM en tareas de seguridad pública y seguridad ciudadana. Desde una perspectiva de seguridad nacional Tamaulipas es una entidad federativa en la que el narcotráfico tiene el control territorial y económico, y dónde el uso de las Fam se ha justificado como una necesidad para que el Estado recupere la gobernabilidad. Se destaca que el problema de violencia que vive esta entidad se deriva del narcotráfico y la delincuencia organizada; no obstante, el análisis se centra en la intervención del Estado para garantizar la "paz".

\subsubsection{Tamaulipas: entre el fuego cruzado}

Tamaulipas cuenta con una posición geográfica estratégica para los grupos que se dedican al tráfico de mercancías y de drogas, ya sea por la vía terrestre o marítima. ${ }^{9}$ Unido a esto, desde finales de la década de 1940 en la zona de Tamaulipas ya se había tendido una amplia red de contrabando y corrupción, que más adelante tomaría fuerza con el aumento de la demanda de drogas por parte de la clase media estadounidense y por la guerra de Vietnam (Saldivar, 2016).

Durante el gobierno de Vicente Fox, la idea de un Estado fragmentado por el narcotráfico se fortaleció a raíz de las batallas por el control territorial que emprendió el llamado Cártel de Sinaloa contra sus competidores del denominado Cártel del Golfo, entre 2004 y 2005, en Nuevo Laredo; sacando a la luz no solo la violencia, sino también la debilidad y la corrupción de las instituciones del Estado.

9. Su amplia frontera con Texas, sus cinco aeropuertos internacionales, sus dos puertos marítimos:Tampico y Altamira,y su extenso litoral en el Golfo de México lo convierten en un territorio propicio para el tráfico de estupefacientes (Saldívar, 2016). Según datos del Secretario Ejecutivo del Sistema Nacional de Seguridad Pública, esta es una de las entidades federativa con mayor índice delictivo por cada 100 mil habitantes, y los delitos de homicidio, secuestro y extorsión son los más recurrentes. 
Riesgos de la militarización de la seguridad como respuesta a la violencia derivada del narcotráfico. El caso Colombia y México

Estas disputas dispararon los índices de violencia en Tamaulipas; las desapariciones forzadas en la región son muestra de esta situación. Por ello, la estrategia de militarización de la seguridad federal se orientó a bajar o contener los índices delictivos, incluidos homicidio, secuestro y extorsión; sin embargo, los resultados han sido magros.

Según Guerrero (2015), los homicidios vinculados al crimen organizado en Tamaulipas aumentaron en un 11.1\% de 2013 a 2014, lo que coloca a esta entidad federativa como la cuarta más violenta a escala nacional, por debajo de Baja California Sur, Coahuila y Guanajuato. ${ }^{10}$

Por otro lado, y como resultado de la violencia en esta entidad, se ha presentado un fenómeno de desplazamiento creciente de la población, dentro o fuera del país, hacia territorios considerados más seguros. Este desplazamiento de la población, según Saldivar (2016), ha impactado de manera negativa en la economía del estado de Tamaulipas, así como en la ruptura del tejido social. Todo esto ha facilitado el uso de las FAM, considerada por el discurso estatal como coadyuvante en las tareas de orden civil. No obstante, esta función residual se ha ido convirtiendo en una función central en materia de seguridad; el problema siguen siendo los ámbitos de actuación y competencia que tienen las FAM en materia de seguridad pública y ciudadana. ${ }^{11}$

La política de tolerancia del narcotráfico por parte del Estado mexicano, durante el siglo pasado, fue la constante; esto se debe, entre otras causas, al frágil andamiaje del sistema de justicia en México. Por ello, cuando Felipe Calderón le declara la guerra al narcotráfico y pasa a una política de

10. Según el Índice de Paz México, en su último informe de 2020, los cinco estados que registran una mayor tasa de homicidios, delitos cometidos con armas de fuego y crímenes de la delincuencia organizada son: Baja California, Colima, Quintana Roo, Chihuahua y Guanajuato (IPM, 2020).

1 I. Otro argumento para legitimar la militarización de la seguridad en Tamaulipas son las pugnas internas entre el cártel del Golfo y lo que fue su brazo armado, los Zetas, por el control territorial. 
confrontación abierta y directa contra el narco, al mismo tiempo debió fortalecer esta debilidad institucional, pues como señala Chabat (2010), la "estrategia" de combatir al narco y fortalecer las instituciones del Estado al mismo tiempo no podría ser una tarea exitosa; por lo tanto, el resultado automático de esta política de confrontación terminó por desatar una violencia que el Estado mexicano no ha podido contener y cuyos costos, en términos políticos y sociales, han sido muy altos.

El argumento de la centralización del poder político es fundamental para entender cómo es que el partido hegemónico controló la violencia producida por el narcotráfico. De esta manera, la relación entre las autoridades y los grupos criminales, para la regulación y la organización del mercado, era más sencilla, lo que permitió a estos grupos desarrollar enclaves de producción y facilitar su trasiego al mercado estadounidense. La estabilidad de esta relación se basó en reglas informales, compromisos y obligaciones por parte de ambos (Palacios y Serrano, 2010).

Esta relación generaba equilibrio y ambas partes salían ganando, los empresarios criminales le daban certidumbre a su negocio, al obtener seguridad por parte de las fuerzas de seguridad y protección política, y la élite política podía controlar el negocio. Esta interdependencia no le permitió al Estado ver con claridad que el narcotráfico, a la larga, podía representar una gran amenaza para el orden político y social del país.

La estrategia que instrumentó Felipe Calderón provocó, como señala Escalante (2009), que aumentara la tensión en el sistema de relaciones sociales y se multiplicara el conflicto; en esta tensión, la intervención del ejército en tareas de seguridad pública y ciudadana se justificaba plenamente. Entonces, siguiendo el argumento de Chabat (2010), las acciones gubernamentales emprendidas por Calderón rompieron los equilibrios entre las organizaciones 
Riesgos de la militarización de la seguridad como respuesta a la violencia derivada del narcotráfico. El caso Colombia y México

criminales, y todo parecería indicar que, para reducir estos niveles de violencia, el Estado debería regresar a su política de tolerancia hacia el narcotráfico.

$\mathrm{Al}$ involucrarse las FAM en el combate al narcotráfico y el crimen organizado, el principal problema ha sido en materia de DDHH, pues han cometido numerosas violaciones en contra de la población, entre las cuales se cuentan desapariciones forzadas, asesinatos y ejecuciones, tortura, abusos sexuales, violaciones de mujeres indígenas y aprehensiones arbitrarias en varias entidades federativas, entre las que se destacan el estado de México, Guerrero y Michoacán. El problema es que muchas de las víctimas de estos abusos no están involucradas en el mundo del narcotráfico y la delincuencia organizada (Alvarado y Zaverucha, 2010).

\section{Conclusiones}

La incapacidad de los gobiernos mexicano y colombiano para asumir sus responsabilidades de garantizar protección y proveer las necesidades básicas de la población hoy tiene en crisis su soberanía; no solo por la pérdida de poder, expresada en el limitado control territorial y social con que cuentan, sino también por la poca responsabilidad que asumen en materia de prevención. Incapacidad que solapan tras un discurso de securitización con el que prometen devolverán el orden interno y reducirán las amenazas, claro, sin mencionar que esto se hace a costa de la restricción de derechos. Sin embargo, olvidan nuestros países los riesgos del enfoque militarista, ya ampliamente estudiados por la Escuela de Copenhague, en materia de pérdida del control democrático y aumento del poder de las élites, dos problemáticas que hoy son evidentes en el caso colombiano y mexicano, donde, por un lado, se restringen libertades en pro de la seguridad y, por otro, las élites tradicionales y emergentes, muchas de estas últimas ligadas a economías ilegales, ganan poder, en 
un juego perverso donde la ciudadanía solo termina siendo legitimadora de la oferta de seguridad impuesta bajo el rótulo de seguridad ciudadana.

Es así como la normalización discursiva alrededor de la guerra contra las drogas, anclada en amenazas creadas institucionalmente, amplía las esferas del accionar militar, apalancado en su par en el escenario de seguridad internacional: la lucha contra el terrorismo. Esto permite que la función policial y la función de guerra lleguen a un punto de indistinción, en el cual, como ocurre hoy en Colombia con la propuesta de Ejército Multimisión, y en el caso de México con la Ley de la Guardia Nacional, la seguridad ciudadana sea una responsabilidad que pueda ser asumida tanto por la policía como por fuerzas militares. En consonancia con la idea de biopolítica como gestión gubernamental de la población, es innegable que, en los casos de estudio, las amenazas construidas y el imaginario de inseguridad propagado son producto del discurso institucional que sostiene una particular política de seguridad militarista, con la que se pretende mantener el statu quo de las élites, a partir de la idea de que es indispensable la intervención del Ejército, justificada por la razón gubernamental.

La incorporación de las fuerzas militares en la esfera de la seguridad interior o ciudadana, sostenida en el supuesto de que los actos de violencia realizados por grupos vinculados al crimen organizado trastocan la soberanía de los Estados y representan un riesgo, termina por legitimar un Estado de excepción permanente que exige el accionar militar en aras de mantener un orden interno, sin estimar el peligro permanente que implica el accionar militar en materia de vulneración de los DDHH, por su vocación de uso irrestricto de la fuerza.

En ambos casos, Colombia y México, es fundamental la reflexión sobre los discursos de seguridad y las relaciones de poder construidas desde las amenazas, que justifican el 
Riesgos de la militarización de la seguridad como respuesta a la violencia derivada del narcotráfico. El caso Colombia y México

uso indefinido e ilimitado de la fuerza. En el caso de México, se pretende dar certeza jurídica a las FAM a través de una Ley de la Guardia Nacional, la cual se está cuestionando fuertemente por la opinión pública, no solo por la forma en que se integró a la Guardia Nacional con las policías del Ejército y la Marina, y con los miembros de la extinta Policía Federal, así como por sus mandos militares, sino también porque con el acuerdo emitido el 11 de mayo de 2020 por el Presidente de la República se dispone de la Fuerza Armada permanente para llevar a cabo tareas de seguridad pública, situación que permanecerá hasta marzo de 2024. Con este acuerdo, en el fondo se pretende establecer un Estado de excepción permanente, a pesar de que no se reconozca como tal.

Distintos organismos defensores de DDHH, incluida la CIDH (2009), han planteado la necesidad de valorar el uso de las fuerzas militares en temas de seguridad pública, para que esto no se convierta en una práctica común. Estas organizaciones instan a avanzar en el fortalecimiento de las fuerzas policiales. Existe evidencia empírica de que el enfoque securitista no está disminuyendo la criminalidad, y el actuar permanente de los militares atenta contra la consolidación del sistema democrático, al incrementarse el poder de los militares a la par que se disminuye la capacidad de control de las instituciones civiles. La temporalidad de su participación es otro elemento que trastoca el control democrático y el respeto por los DDHH.

En síntesis, los casos que aquí se presentaron demuestran cómo, tanto en Colombia como en México, el Estado justifica la incursión de las fuerzas militares en tareas de seguridad pública y seguridad ciudadana desde una perspectiva de seguridad nacional, situación que está legitimada internacionalmente a través de valores universales, en aras de alcanzar la paz y el orden deseados. Este traslado del discurso internacional a la esfera nacional y local da 
paso a la configuración de una "guerra justa", al convertir amenazas internas en riesgos para la soberanía, y produce finalmente un re-balanceo de las relaciones de poder que subyacen al discurso de seguridad, a partir de recursos de biopolítica que garantizan la disciplina y la obediencia de la población.

Bibliografía

Agamben, Giorgio (2005). Estado de excepción. I a reimp. Buenos Aires:Adriana Hidalgo editora.

Aricapa, R. (20I5). Crónica de una guerra urbana. De Orión a la Escombrera. Bogotá: Ediciones B.

Angarita Cañas, P. E. (2013). Propuestas de seguridad desde organizaciones de base en contextos violentos. Nuevo pensamiento sobre seguridad en América Latina. Hacia la seguridad como un valor democrático. Colombia: CLACSO. Alvarado, A. y J. Zaverucha (2010). "La actuación de las fuerzas armadas en la seguridad pública en México y Brasil: una visión comparada". En A. Alvarado y M. Serrano (Coord.). Los grandes problemas de México. Seguridad nacional y seguridad interior. México: El Colegio de México.

Astorga, L. (2007). Seguridad, traficantes y militares: el poder y la sombra. México:Tusquets.

Carrillo Flórez, F. (2007). "Seguridad ciudadana en América Latina: Un bien público cada vez más escaso". En Pensamiento Iberoamericano. España: Agencia Española de Cooperación Internacional y Fundación Carolina.

Centro Nacional de Memoria Histórica — CNMH (20I4). La huella invisible de la guerra. Desplazamiento forzado en la Comuna 13. Bogotá:Taurus.

CIDH (2009). "La intervención de las fuerzas armadas en tareas de seguridad ciudadana". En CIDH. Informe sobre la seguridad ciudadana y derechos humanos. Disponible en:http://www.oas.org/es/cidh/docs/pdfs/seguridad\%20 ciudadana\%202009\%20esp.pdf. 
CINEP (2003). Noche y niebla. Caso tipo núm. 2. Bogotá: CINEP. Disponible en: https://www.nocheyniebla.org/wp-content/uploads/ul/casotipo/Comuna I3.pdf. Consultado: 10 de abril de 2017.

Corva, D. (2009). "Bio-power and the Militarization of the Police Function. ACME”, An International e Journal for Critical Geographies, 8 (2), I6I-I75.

Chabat, J. (2010). "La respuesta del gobierno de Felipe Calderón al desafío del narcotráfico: entre lo malo y lo peor”. En A. Alvarado y M. Serrano (Coord.). Los grandes problemas de México. Seguridad nacional y seguridad interior. México: El Colegio de México.

Churruca, C. (20I3). "La seguridad humana como vínculo entre la acción humanitaria y la construcción de paz”. En K. Pérez e I. Mendia (Coord.). Seguridad humana: aportes críticos al debate teórico y político. Madrid:Tecnos.

Delgado Barón, M. (2008). “Reconceptualizando la seguridad: cambio de dilemas y amenazas". Revista de Relaciones Internacionales, Estrategia y Seguridad, 3 (2). Colombia: Universidad Militar Nueva Granada.

Defensoría del Pueblo (2004). Desplazamiento intraurbano como consecuencia del conflicto armado en las ciudades. Bogotá.

Duncan, G. (20I4). Más que plata o plomo. El poder político del narcotráfico en Colombia y México. Bogotá: Debate.

Enciso, F. (2010). "Los fracasos del chantaje. Régimen de prohibición de drogas y narcotráfico”. En A.Alvarado y M. Serrano (Coord.). Los grandes problemas de México. Seguridad nacional y seguridad interior. México: El Colegio de México.

Escalante Gonzalbo, F.“(2009). ¿Puede México ser Colombia? Violencia, narcotráfico y Estado”. Nueva Sociedad, (220), 84-96. 
Bibliografía

Foucault, M. (2006). Seguridad, territorio, población. Curso en el Collège de France: 1977-1978. Buenos Aires: Fondo de Cultura Económica.

Gil, M. y M.Alonso (2009). Paramilitarismo y conflicto urbano: relaciones entre el conflicto político armado nacional y las violencias preexistentes en la ciudad de Medellín: 19972005. Trabajo de grado para optar al título de magister. Universidad de Antioquia.

Guerrero, E. (2015). “Bajó la violencia?”. Nexos, octubre 27 de 2016. Disponible en: http://www.nexos.com. $\mathrm{mx} / \mathrm{p}=24035$. Consultado: I de agosto de 2017.

Hardt, M.y T. Negri (2000) Imperio. Massachusetts: Harvard University Press, Cambridge.

Hobbes,T. (I980). Leviatán, o la materia, forma y poder de una república. México: Fondo de Cultura Económica.

Índice de Paz México (IPM) (2020). Identificar y medir los factores que impulsan la paz. Sidney, abril. Disponible en: indicedepazmexico.org.

Naciones Unidas (2003). Grupos e individuos específicos, éxodos en masa y personas desplazadas. Informe del Representante del Secretario General sobre los desplazados internos, Francis M. Deng, presentado de conformidad con la resolución 2002/56 de la Comisión de Derechos Humanos. Disponible en: https://www. acnur.org/fileadmin/Documentos/BDL/2003/2265.pdf. (2009). Hacer efectiva la responsabilidad de proteger. Informe del Secretario General. Disponible en http:// responsibilitytoprotect.org/Report\%20of\%20the $\% 20$ SG\%20Implementing\%20the\%20RtoP\%20ESPANOL.pdf. Medina Gallego, C. (200I). ELN: Una historia de los orígenes, Bogotá: Rodríguez Quito Editores.

Montero Bagatella, J. C. (20I3). "El concepto de seguridad en el nuevo paradigma de la normatividad mexicana". Región y Sociedad, xxv, 58, 203-238. 
Nateras González, M. e I. Tinoco García (2014). "ConsBibliografía trucción de la ciudadanía en el nuevo paradigma de seguridad”. En J.L. Estrada (Coord.). Seguridad ciudadana: visiones compartidas. Toluca: UAEM-IAPEM.

Palacios, M. y M. Serrano (20I0). Colombia y México: las violencias del narcotráfico. En A.Alvarado y M. Serrano (Coord.). Los grandes problemas de México. Seguridad nacional y seguridad interior. México: El Colegio de México.

Paoli Bolio, I. (2008).“Evolución del narcotráfico en México”. El Bien Común, (163), 98-II0.

Pérez, K. (20I3). "Seguridad humana y estudios críticos de seguridad: de la cooptación a la emancipación”. En K. Pérez e I. Mendia. Seguridad humana: aportes críticos al debate teórico y político. Madrid:Tecnos.

Piñeyro, J. L. (20I0). "Las fuerzas armadas mexicanas en la seguridad pública y la seguridad nacional”. En A. Alvarado y M. Serrano (Coord.). Los grandes problemas de México. Seguridad nacional y seguridad interior. México: El Colegio de México.

PNUD (1994). Informe sobre desarrollo humano 1994. Disponible en: http://hdr.undp.org/sites/default/files/hdr_1994_ es_completo_nostats.pdf.

Ramos García, J. M. (2005). "Seguridad ciudadana y la seguridad nacional en México: hacia un marco conceptual”. Revista Mexicana de Ciencias Políticas y Sociales, XLVII (194), 33-52.

Ravelo, R. (20I I). El narco en México. Historia e historias de una guerra. México: Grijalbo.

Saldivar, Hadad, N. (2016). Análisis de la política pública de seguridad federal (2006-20I2); la presencia militar en la zona sur de Tamaulipas. Tesis de doctorado en Ciencias Sociales, Universidad Autónoma del Estado de México. Sandoval,J. (2000).“Militarización, seguridad nacional y seguridad pública en México”. Espiral, Estudios sobre Estado y Sociedad, vI (18), I83-222. 
Bibliografía

Šimonović, I. (s/f). “La responsabilidad de proteger”. Crónica onU. Disponible en: https://www.un.org/es/chronicle/ article/la-responsabilidad-de-proteger.

Valdez,J. (2009). Miss Narco. Belleza, poder y violencia. México: Aguilar.

Valencia, P. (20I6). "La respuesta humanitaria entre los debates teóricos y la crisis de la gobernabilidad en los contextos urbanos latinoamericanos. El caso de MedeIlín”. En I. Mosel, C. Bennet y A. Krebs. Aproximaciones a la historia del humanitarismo en América Latina y el Caribe. London: Overseas Development Institute. Working Paper.Weber, M. ( 1991$)$. El político y el científico. Madrid: Alianza editorial. 